\title{
Survival of an infant with amnion rupture sequence: a dilemma for clinicians
}

Termination of pregnancy should be legalised when extensive, surgically uncorrected or inevitably fatal fetal malformations are confirmed

\section{V C de Silva ${ }^{1}$, D C Gooneratne ${ }^{2}$, M D P Gooneratne ${ }^{3}$ and H Ediriweera ${ }^{4}$}

\section{Introduction}

Amnion rupture in early pregnancy results in severe anomalies such as anencephaly, encephalocoele, exencephaly, acrania, facial clefts and absence of limbs $(1,2)$. Most affected fetuses abort in the second trimester, are stillborn or die soon after birth $(1,3)$. We report an infant with amnion rupture sequence, who survived for 9 weeks after birth. A Medline search failed to reveal documentation of survival of a baby with severe craniofacial anomalies of this sequence for so long.

\section{Case report}

A $3.2 \mathrm{~kg}$ female infant was delivered by caesarian section in a 26-year old primigravida. Her skull vault was absent. The brain was covered only by scalp. There were two encephaloceles on the forehead (Figure). She had blepherophimosis, absence of the nose, cleft lip and palate, and clefts in the region of the nose and forehead with attached amniotic bands. There was amputation of the thumbs and index fingers. The toes were hypoplastic with attached amniotic bands. Ultrasound scan of the brain showed dilation of lateral and third ventricles. The right lateral ventricle communicated with the encephalocoeles. The posterior cranial fossa was small. The baby was otherwise normal. She was fed with expressed breast milk given by spoon and cup. She survived for 9 weeks.

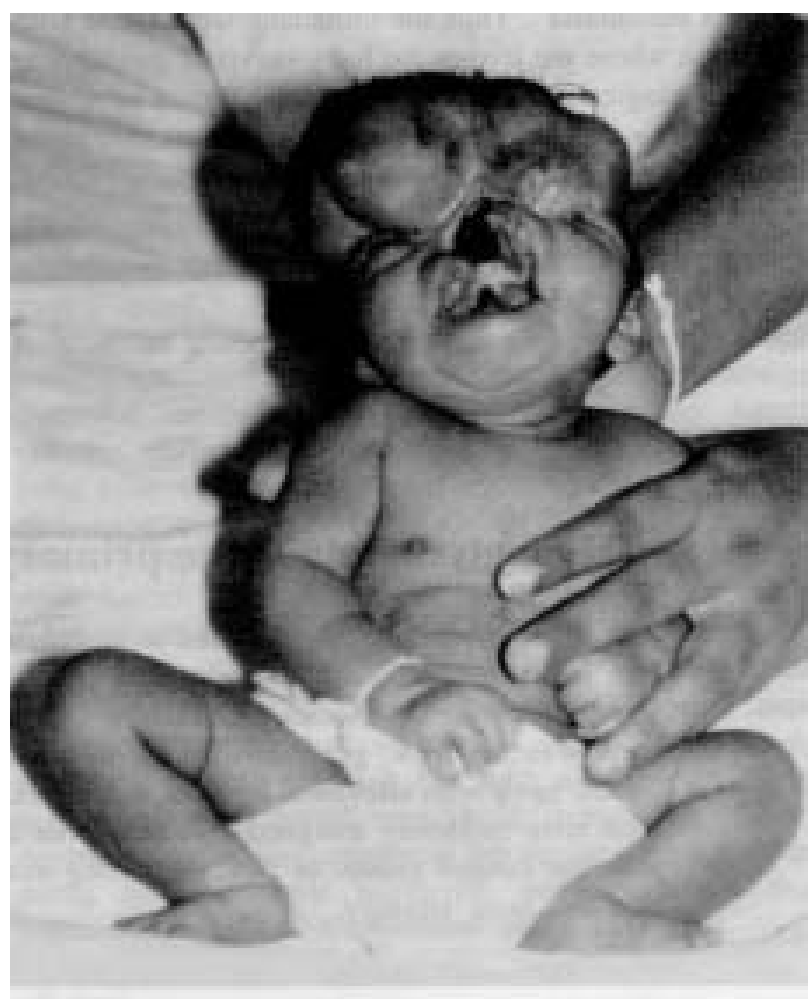

Figure. Severe facial cleft and encephalocoele.

${ }^{1}$ Senior lecturer and ${ }^{4}$ Research assistant, Department of Pathology, Faculty of Medicine, University Colombo; ${ }^{2}$ Paediatrician, ${ }^{3}$ Obstetrician and Gynaecologist, De Soysa Hospital for Women, Colombo. (Correspondence: MVC de S, tel: 01 645575, 077 792077. Submitted 25 August 2001, revised version accepted 2 January 2002). 


\section{Discussion}

Amnion rupture sequence should be distinguished from a syndrome, as the recurrence risk is negligible $(1,2)$. Abnormalities of this sequence arise from physical interruption of normal development or from tethering, compression and injury to previously formed structures by amniotic bands (1). The reported causes for amnion rupture include physical trauma in early pregnancy (1), connective tissue disorders such as Ehlers-Danlos syndrome and severe osteogenesis imperfecta in the infant (4), ingestion of oral contraceptives in early pregnancy (5), and amniocentesis (6). Infection does not seem to be a factor in the aetiology of amnion rupture (1).

This case exemplifies some ethical issues involved in the management of newborns with inevitable lethal congenital malformations. The clinicians had to transfer the infant from the premature baby room to the mother as the feeding demands increased. The mother refused to see and handle the baby. Looking after a severely abnormal baby in a ward with normal neonates caused severe distress to her. The hospital administrators refused to discharge the mother and keep the baby in hospital for legal reasons. Advice given to the parents to take the baby home seemed unethical, knowing the psychological trauma the parents would have to face in showing the baby to family and friends. Surgery to correct the malformations could not be contemplated, as it would have amounted to "indirect euthanasia". Thus the clinicians were faced with a situation where the longer the baby survived greater was the psychological trauma to the parents. Hence provision to look after such babies after discharging the mother home should be available in our hospitals.
This tragedy could have been prevented if a therapeutic termination was performed following prenatal ultrasound diagnosis of the severe anomalies. However, the present abortion law of the country does not allow this. Attempts to reform this law failed when the 1995 Penal Code Amendment was withdrawn (7). We feel that a fresh attempt should be made to legalise therapeutic termination of pregnancies complicated by extensive, surgically uncorrectable or invariably fatal, fetal malformations. Mandatory confirmation of malformations by necropsy examination will prevent abuse of such a law.

\section{References}

1. Kelling JW, Boyd PA. Congenital malformations, prenatal diagnosis and fetal examination. In: Keeling JW, ed. Fetal and neonatal pathology. $2^{\text {nd }}$ edition. London: Springer-Verlag 1993; 141-2.

2. de Silva MVC, Lakshman WDH. Gooneratne DC. Early amnion rupture sequence, often misdiagnosed as a syndrome. Ceylon Medical Journal 1997; 42: 181-2.

3. Kalousek DK, Bamforth S. Amnion rupture sequence in previable fetuses. American Journal of Medical Genetics 1988; 31: 63-73.

4. Young ID, Lindenbaum RH, Thompson EM, Pembery ME. Amniotic bands in connective tissue disorders. Archives of Diseases of Childood 1985; 60: 1061-3.

5. Ossipoff V, Hall D. Etiologic factors in the amniotic band syndrome: a study of 24 patients. Birth Defects 1977; 13: 117-2.

6. Rehder H, Weitzel H. Intrauterine amputations after amniocentesis. Lancet 1978; i: 382.

7. Sri Lanka Hansard.19th September 1995; 89-128.

\section{Hypoglycaemia is the primary complication of sulphonylureas}

The primary complication of the sulfonylureas is hypoglycemia, which is a particular problem in patients whose glucose level is under tight control, the elderly, and persons who perform intermittent intense excercise or commonly miss or delay meals. Grave concerns about increased cardiovascular risk, generated by the ill-fated University Group Diabetes Program of the early 1970s, have been alleviated by most subsequent evidence, including the UKPDS, in which patients who were randomly assigned a sulfonylurea did not have a higher rate of cardiovascular events than the control group. In fact, the strong trend was toward reduced cardiovascular events with this treatment strategy.

Ahmann AJ, Riddle MC. Current oral agents for type 2 diabetes. Postgraduate Medicine 2002; 111: 34 . 